\title{
Hereditary Porcine Membranoproliferative Glomerulonephritis Type II Is Caused by Factor H Deficiency
}

\author{
Kolbjørn Høgåsen, * Johan H. Jansen, ${ }^{\ddagger}$ Tom E. Mollnes, ${ }^{\S}$ Jan Hovdenes, ${ }^{*}$ and Morten Harboe* \\ *Institute of Immunology and Rheumatology, The National Hospital, University of Oslo, N-0172 Oslo, Norway; ${ }^{\ddagger}$ Department of \\ Morphology, Genetics, and Aquatic Biology, Section of Pathology, Norwegian College of Veterinary Medicine, POB 8146 Dep., \\ $\mathrm{N}-0033$ Oslo, Norway; ${ }^{\S}$ Department of Immunology and Transfusion Medicine, Nordland Central Hospital, and University of \\ Tromsø, N-8017 Bodø, Norway
}

\begin{abstract}
We have recently described hereditary membranoproliferative glomerulonephritis type II in the pig. All affected animals had excessive complement activation, revealed as low plasma C3, elevated plasma terminal complement complex, and massive deposits of complement in the renal glomeruli, and eventually died of renal failure within 11 wk of birth. The aim of the present study was to investigate the cause of complement activation in this disease. Transfusion of normal porcine plasma to affected piglets inhibited complement activation and increased survival. Plasma was successively fractionated and the complement inhibitory effect of each fraction tested in vivo. A single chain $150-\mathrm{kD}$ protein which showed the same complement inhibitory effect as whole plasma was finally isolated. Immunologic cross-reactivity, functional properties, and $\mathrm{NH}_{2}$-terminal sequence identified the protein as factor $\mathrm{H}$. By Western blotting and enzyme immunoassay, membranoproliferative glomerulonephritisaffected piglets were demonstrated to be subtotally deficient in factor $H$. At 1 wk of age, median (range) factor $H$ concentration was $1.6 \mathrm{mg} /$ liter $(1.1-2.3)$ in deficient animals ( $n$ $=13$ ) and $51 \mathrm{mg} /$ liter (26-98) in healthy littermates ( $n$ $=52$ ). Our data show that hereditary porcine membranoproliferative glomerulonephritis type II is caused by factor H deficiency. (J. Clin. Invest. 1995. 95:1054-1061.) Key words: glomerulonephritis - mesangiocapillary • complement activation - complement inactivators - complement pathway, alternative $\cdot$ hereditary diseases
\end{abstract}

\section{Introduction}

Membranoproliferative glomerulonephritis (MPGN), ${ }^{1}$ also called mesangiocapillary glomerulonephritis, is a relatively rare

Address correspondence to Kolbjørn Høgåsen, Institute of Immunology and Rheumatology, Fr Qvamsgt 1, N-0172 Oslo, Norway. Phone: 4722-86-96-80; FAX: 47-22-20-72-87.

Received for publication 8 June 1994 and in revised form 7 November 1994.

1. Abbreviations used in this paper: $\mathrm{AU}$, arbitrary unit; $\mathrm{C}$, complement; EACA, $\epsilon$-amino- $n$-caproic acid; FH, factor H; HFH, human FH; HRP, horseradish peroxidase; MPGN, membranoproliferative glomerulonephritis; NHS, normal human serum; NPS, normal procine serum; PEG, polyethylene glycol; $\mathrm{PFH}$, porcine FH; TCC, terminal complement complex.

J. Clin. Invest.

(C) The American Society for Clinical Investigation, Inc.

0021-9738/95/03/1054/08 $\$ 2.00$

Volume 95, March 1995, 1054-1061 kidney disease characterized by a combination of glomerular capillary wall thickening and a variable degree of mesangial cell proliferation and increased matrix. Regularly heavy deposits of complement $(\mathrm{C})$, in the mesangium and along the capillary wall is found (1). MPGN is divided into three types by electron microscopic evaluation of the glomerulus basement membrane $(2,3)$. Type $I$ is characterized by subendothelial deposits, type II by intramembranous dense deposits, and type III by both subendothelial and subepithelial deposits. Type I and III are probably variants of the same disease (4), in which glomerular deposition of immune complexes that activate the classical pathway of $\mathrm{C}$ seems to play a key role (1). By contrast, deposits of immune complexes are absent in MPGN type II. MPGN type II is, however, associated with alternative pathway $\mathrm{C}$ activation, usually caused by $\mathrm{C} 3$ nephritic factors, IgG autoantibodies which stabilize the alternative $\mathrm{C} 3$ convertase, $\mathrm{C} 3 \mathrm{bBb}$ (5). C3 nephritic factors potently activating the terminal pathway of $\mathrm{C}$ have been described (6).

MPGN type II has been reported in two children deficient in factor $\mathrm{H}(\mathrm{FH})(7)$. FH is an alternative pathway regulatory protein with a normal serum concentration in humans of $\sim 500$ $\mathrm{mg} /$ liter (8). It has several effects: it competes with factor B for $\mathrm{C} 3 \mathrm{~b}$ binding, it disassembles $\mathrm{C} 3$ convertase by facilitating the dissociation of $\mathrm{Bb}$ from $\mathrm{C} 3 \mathrm{~b}$, it inhibits $\mathrm{C} 5$ convertase by competing with $\mathrm{C} 5$ for $\mathrm{C} 3 \mathrm{~b}$ binding, and it acts as a cofactor for factor-I-mediated inactivation of $\mathrm{C} 3 \mathrm{~b}$ to $\mathrm{iC} 3 \mathrm{~b}$ and further into $\mathrm{C} 3 \mathrm{c}$ and $\mathrm{C} 3 \mathrm{dg}(9-12)$. Deficiency of FH leads to consumption of C3 and factor B (13). The levels of terminal components may be normal (13), but are low in most patients $(7,11$, $14,15)$.

We have recently described the first animal model for MPGN type II in piglets of the Norwegian Yorkshire breed (16, 17). Affected piglets appeared clinically healthy at birth and for the first few weeks of life. Thereafter they failed to thrive with growth retardation due to rapidly progressive glomerulonephritis and eventually they all died of renal failure within $72 \mathrm{~d}$ (median $37 \mathrm{~d})$ after birth $(n=25)$. The kidneys showed extensive glomerular proliferation and profound thickening of the glomerular capillary wall. Large amounts of dense deposits were consistently found within the glomerular basement membrane being up to $1,250 \mathrm{~nm}$ thick, compared to $150-200 \mathrm{~nm}$ in the normal animals. Excessive $\mathrm{C}$ activation was observed in affected pigs, revealed as low plasma $\mathrm{C} 3$, elevated plasma terminal complement complex (TCC), and massive deposits of $\mathrm{C}$, but not immunoglobulins, along the capillary walls of renal glomeruli. The disease was hereditary (16), with a simple autosomal recessive pattern and complete penetrance (Jansen, J. H., K. Høgåsen, and A. M. Grøndahl, unpublished results ). No disease was detected in heterozygous carriers of the MPGN trait. 
We have previously suggested that this porcine MPGN type II may be caused by an inherited deficiency of a $\mathrm{C}$ regulatory protein (17). The aim of the present study was to clarify the etiology of the disease.

\section{Methods}

Animals. 13 piglets affected by MPGN type II were produced by test matings of parental animals associated with the disease as previously described (16). Affected animals were identified at $1 \mathrm{wk}$ of age (4-10 d) by demonstration of low plasma C3 (median $4.2 \%$ of a pool, range 2.4-8.7\%) and elevated plasma TCC (median 13.9 arbitrary unit (AU)/ $\mathrm{ml}$, range $8.0-25.3 \mathrm{AU} / \mathrm{ml}$ ) as described previously (17). Their healthy littermates $(n=52)$ had a median C3 concentration of $51.8 \%$ (range 24.4-150.4\%), and a median TCC concentration of $1.0 \mathrm{AU} / \mathrm{ml}$ (range 0.4-2.4 AU/ml). Healthy 3-wk-old control piglets not associated with the disease $(n=15)$ had a median C3 concentration of $89.4 \%$ (range 53.6-107.4\%), and a median TCC concentration of $0.8 \mathrm{AU} / \mathrm{ml}$ (range 0.6-1.0 AU/ml) (17). The aberrant C profile of the MPGN-affected piglets persisted until death. In all MPGN piglets the diagnosis was confirmed by autopsy with the following findings: ( $a$ ) glomerular hypercellularity and thickened glomerular capillary wall; $(b)$ dense deposits within the glomerular basement membrane; and $(c)$ heavy deposits of C3 and TCC along the capillary wall. All nonaffected littermates remained healthy until they were slaughtered $\sim 6$ mo old. All passed the routine meat inspection at the slaughterhouse performed by an experienced veterinarian. MPGN is definitely a rare finding in slaughter pigs, since no macroscopic or light microscopic renal changes compatible with that diagnosis were detected among 668 pigs examined at the same slaughterhouse (18).

Ethics. The use of animals in this study was approved by the committee for animal experiments.

Materials. Benzamidine $\mathrm{HCl}$, zymosan A, Coomassie brilliant blue $\mathrm{R}, \mathrm{PMSF}, 3,3$ 'diaminobenzidine, $\epsilon$-amino- $\boldsymbol{n}$-caproic acid (EACA), and Tween 20 were purchased from Sigma Chemical Co. (St. Louis, MO). Purified human $\mathrm{C} 3$ and $\mathrm{FH}, \mathrm{mAb}$ against human $\mathrm{C} 3 \mathrm{c}$ and $\mathrm{C} 6$, and goat antiserum against human $\mathrm{C} 3$ and $\mathrm{FH}$ were purchased from Quidel Corp. (San Diego, CA). Rabbit antiserum against porcine C3 was purchased from Organon Teknika BCA/Cappel (West Chester, PA). Horseradish peroxidase (HRP)-linked donkey anti-rabbit Ig, HRP-linked sheep anti-mouse Ig, and rainbow mol wt markers were purchased from Amersham International (Little Chalfont, United Kingdom). HRP-linked mouse anti-goat Ig was purchased from Jackson ImmunoResearch Laboratories Inc. (West Grove, PA). Q Sepharose Fast Flow, Lysine Sepharose 4B, Sepharose CL-6B, Protein G Sepharose 4 Fast Flow, Protein A Sepharose CL-4B, Resource Q, and low mol wt standards were purchased from Pharmacia LKB Biotechnology Inc. (Sollentuna, Sweden). Mol wt protein standards for SDS gel electrophoresis were purchased from Bio Rad Laboratories (Richmond, CA). Polyethylene glycol (PEG) 4000 was purchased from Prolabo (Paris, France). An mAb isotyping kit (SAB clonotyping system II) was purchased from Southern Biotechnology Associates, Inc. (Birmingham, AL).

Enzyme immunoassays for C3 and TCC. Enzyme immunoassays for porcine C3 and TCC were performed as described (17). Briefly, in the C3 assay, a rabbit antiserum against porcine C3 was used as capture antibody. A pool of porcine plasma from 3-wk-old healthy Yorkshire piglets $(n=15)$ from a population spared for MPGN was used as standard, defining $100 \%$. An mAb against human $\mathrm{C} 3 \mathrm{c}$ was used as secondary antibody. In the TCC assay, our own mAb aE11 (anti-C9 neoepitope) was used as capture antibody (19), zymosan-activated human serum was used as standard, defining $1,000 \mathrm{AU} / \mathrm{ml}$, and an $\mathrm{mAb}$ against human $\mathrm{C} 6$ was used as detecting antibody.

Nephritic factor test. A test for nephritic factor, or any other form of C-activating factor in serum was performed as follows: 1 vol of serum from MPGN-affected piglets ( $n=7$, median age $1 \mathrm{wk}$ ), or from healthy, age-matched littermates $(n=7)$ were mixed with 4 vol normal porcine serum (NPS) and frozen immediately, or incubated for 1,4 , or
$24 \mathrm{~h}$ at $37^{\circ} \mathrm{C}$. PBS was used as a negative control and PBS with zymosan ( $50 \mathrm{~g} /$ liter, final dilution $10 \mathrm{~g} /$ liter) was used as a positive control. The resulting $\mathrm{C}$ activation was evaluated by measuring the TCC concentration of the samples. This approach was feasible since increased TCC formation was a characteristic finding in MPGN-affected piglets.

Preparation of plasma and erythrocytes. Blood was obtained from carbon dioxide-anesthetized slaughter pigs by aortapunction, collected into bottles containing $1 / 10$ vol of $0.1 \mathrm{M}$ sodium citrate, $\mathrm{pH} 7.4$, cooled on ice, and centrifuged within $8 \mathrm{~h}$. Plasma was stored at $-20^{\circ} \mathrm{C}$ and used within $3 \mathrm{mo}$. Erythrocytes were washed in saline and stored at $4^{\circ} \mathrm{C}$ and transfused within $24 \mathrm{~h}$. EDTA-plasma or serum from 20 pigs (age $6 \mathrm{mo}$ ) were pooled and designated normal porcine plasma and NPS, respectively.

Transfusion of plasma or erythrocytes. Plasma transfusions were started at 2 wk age (10-25 d) and repeated once a week, if possible, until the pigs died. Citrated plasma was administered via a veneflon in an auricular vein. For pigs of body wt $<40 \mathrm{~kg}$ the dose was $30 \mathrm{ml} /$ $\mathrm{kg}$, for larger pigs the dose was reduced to $20 \mathrm{ml} / \mathrm{kg}$. The transfusions were finished in 10-90 min depending on how well they were tolerated (e.g., signs of hypocalcemia, shivering, ticks, and cramps). Transfusion of plasma fractions showing similar $\mathrm{C}$ inhibitory effect as whole plasma were counted as plasma transfusions. The dose of transfused washed erythrocytes (hematocrit 0.88 ) was $30 \mathrm{ml} / \mathrm{kg}$ (pigs of wt $10-13 \mathrm{~kg}$ ).

Purification of porcine factor $H(P F H)$. For the plasma fractionation, porcine blood was collected into bottles containing $1 / 30 \mathrm{vol}$ of $0.2 \mathrm{M}$ sodium EDTA, $\mathrm{pH} 7.4$, then cooled on ice, centrifuged, and plasma stored at $-20^{\circ} \mathrm{C}$. All purification procedures were performed at $4^{\circ} \mathrm{C}$.

Precipitation. Frozen plasma was thawed in microwave oven or in cold water and the cryoprecipitate was removed by centrifugation (1,500 $g$ for $30 \mathrm{~min}$ ). The supernatant was diluted with $1 / 20 \mathrm{vol}$ of an enzyme inhibitor solution containing $0.2 \mathrm{M}$ benzamidine $\mathrm{HCl}$ in $1 \mathrm{M} \mathrm{KH}_{2} \mathrm{PO}_{4}$, $\mathrm{pH} 7.4$, and $1 / 100 \mathrm{vol} 0.1 \mathrm{M}$ PMSF in anhydrous isopropanol essentially as described by Hammer et al. (20). The solution was then precipitated stepwise with PEG 4000. First the solution was made 5\% (wt/vol) in PEG 4000 by slow addition, with stirring, of the powder and allowed to equilibrate for $1 \mathrm{~h}$. The precipitate (5\% PEG precipitate) was removed by centrifugation at $4,000 \mathrm{~g}$ for $1 \mathrm{~h}$. The supernatant was thereafter made $16 \%$ in PEG 4,000, equilibrated for another $1 \mathrm{~h}$, and the 5-16\% PEG precipitate was removed by centrifugation. New precipitates were made by repeating the procedure using final PEG 4,000 concentrations of 20 and $45 \%$. In a second purification, more narrow precipitations were performed with PEG concentrations of 1,3 , and $5 \%$, respectively. Generally protein concentrations were calculated by measuring absorbance at $280 \mathrm{~nm}$, using $E_{1 \mathrm{mg} / \mathrm{ml}}=1.0$ for simplicity. However, for the purified protein, $\mathrm{E}_{1 \mathrm{mg} / \mathrm{ml}}=1.42$ as determined for human $\mathrm{FH}(\mathrm{HFH})$ was used (21).

Lysine Sepharose chromatography. The 3-5\% PEG precipitate was dissolved in a buffer containing $30 \mathrm{mM}$ Tris, $100 \mathrm{mM} \mathrm{NaCl}, 10 \mathrm{mM}$ $\mathrm{Na}_{2}$ EDTA, and $5 \mathrm{mM}$ benzamidine $\mathrm{HCl}, \mathrm{pH} 8.7$. The solution was cleared by centrifugation $(27,500 \mathrm{~g}$ for $1 \mathrm{~h})$ and filtered through a 0.8 $\mu \mathrm{m}$ filter before application onto a lysine Sepharose column which was equilibrated with the same buffer $(5 \times 5 \mathrm{~cm}$, linear flow rate $6 \mathrm{~cm} / \mathrm{h})$. Bound protein was eluted with the same buffer adjusted to $200 \mathrm{mM}$ EACA and discarded.

$Q$ Sepharose chromatography (anion-exchange). The effluent from the lysine Sepharose column was collected and made $30 \mathrm{mM}$ in EACA by adding solid powder. The solution was applied to a $\mathrm{Q}$ Sepharose Fast Flow column $(5 \times 28 \mathrm{~cm}$, linear flow rate $6 \mathrm{~cm} / \mathrm{h})$ which had been equilibrated with the same buffer. The column was washed with the buffer until baseline was reestablished. Bound protein was then eluted with a linear gradient $(0-100 \%$ over $16.7 \mathrm{~h})$ of the buffer adjusted to $1 \mathrm{M} \mathrm{NaCl}$.

Gel filtration (Sepharose $C L-6 B$ ). Appropriate fractions from the ion-exchange chromatography were dialyzed against a buffer containing $100 \mathrm{mM} \mathrm{KH}_{2} \mathrm{PO}_{4}, 150 \mathrm{mM} \mathrm{NaCl}, 5 \mathrm{mM} \mathrm{Na}_{2}$ EDTA, and $50 \mathrm{mM}$ EACA, $\mathrm{pH} 7.4$, and $50 \mathrm{ml}$ was applied on a Sepharose CL-6B column $(5 \times 84$ 
$\mathrm{cm}$, linear flow rate $2 \mathrm{~cm} / \mathrm{h}$ ) which had been equilibrated with the same buffer.

Resource $Q$ chromatography (anion exchange). A fraction from gel filtration was dialyzed against a $30-\mathrm{mM}$ Tris $\mathrm{HCl}$ buffer, $\mathrm{pH} 8.7$, and applied on a Resource Q HPLC column $(1.6 \times 3 \mathrm{~cm}$, linear flow rate $90 \mathrm{~cm} / \mathrm{h})$. Bound protein was eluted by a linear gradient $(0-100 \%$ over $15 \mathrm{~min}$ ) of the same buffer adjusted to $0.5 \mathrm{M} \mathrm{NaCl}$.

Protein $G$ Sepharose chromatography. A fraction from Resource $Q$ was applied on a Protein G Sepharose column $(1 \times 5 \mathrm{~cm}$, linear flow rate $40 \mathrm{~cm} / \mathrm{h}$ ). The effluent was dialyzed against $30 \mathrm{mM}$ Tris $\mathrm{HCl} \mathrm{pH}$ 8.7 and reapplied on the Resource $\mathrm{Q}$ column.

Test for $C$ inhibitory activity. Products from the blood and plasma fractionation were administered intravenously to MPGN-affected piglets. Precipitates and chromatographic fractions containing toxic substances were thoroughly dialyzed against PBS before administration to the animals. Blood was sampled before, immediately after, 1 and $8 \mathrm{~h}$ after the treatment, or more frequently. EDTA plasma was then assayed for the content of C3 and TCC. A decreasing TCC level and/or an increasing $\mathrm{C} 3$ level observed within the first $8 \mathrm{~h}$ after the transfusion was finished, was regarded as a $\mathrm{C}$ inhibitory effect.

SDS-PAGE and Western blotting. SDS-PAGE was performed using precasted 8-18\% gradient gels (Excel Gel SDS) and a Multiphor II electrophoresis unit (Pharmacia LKB Biotechnology Inc.). Gels were stained with Coomassie brilliant blue $\mathrm{R}(2.5 \mathrm{~g} / \mathrm{liter})$, or blotted onto $0.45-\mu \mathrm{m}$ pore nitrocellulose using a Multiphor II NovaBlot electrophoretic transfer unit (Pharmacia LKB Biotechnology Inc.). The nitrocellulose was blocked with 3\% BSA over night. The blots were stained with primary antibodies and horseradish peroxidase-linked secondary antibodies, all diluted in PBS containing 1\% BSA. Incubations were for minimum $1 \mathrm{~h}$ at room temperature, and the blots were washed three times for $15 \mathrm{~min}$ in PBS between each incubation. The blots were developed with 3,3 'diaminobenzidine and $\mathrm{H}_{2} \mathrm{O}_{2}$.

Production of rabbit antiserum. Two rabbits were immunized with $50 \mu \mathrm{g}$ each of the purified protein (PFH) in Freund's complete adjuvant and then boosted with the same amount of protein after 4 wk. An IgG fraction from the antiserum was obtained by Protein A affinity chromatography.

Production of $m A b$. Balb/c mice were immunized with purified factor $\mathrm{H}$. Spleen cells were fused with the myeloma cell line X63-Ag 8.653 according to the method described by Galfre and Milstein (22). Screening and selection of clones were performed in microtiterplates which had been coated with the immunisate. One clone (designated 7C3) was selected, expanded, and ascites was produced after intraperitoneal injection in mice. The mAb was purified by PEG precipitation ( $15 \%$ PEG 4,000 at $4^{\circ} \mathrm{C}$ for $1 \mathrm{~h}$ ), followed by ion-exchange chromatography using a Resource Q HPLC column. Isotyping of heavy and light chains was performed using a commercial kit. An immunosorbent was made by coupling $29 \mathrm{mg} \mathrm{mAb}$ to $9 \mathrm{ml} \mathrm{CNBr}$-activated Sepharose 4B.

In vitro tests for $C 3$ c formation. NPS or MPGN-serum were mixed with $10 \mathrm{~g} /$ liter zymosan and incubated under continous rotation at $37^{\circ} \mathrm{C}$ for $24 \mathrm{~h}$. Conversion of $\mathrm{C} 3$ to $\mathrm{C} 3 \mathrm{c}$ was evaluated by Western blotting using antiserum against porcine $\mathrm{C} 3$.

$\mathrm{C} 3 \mathrm{c}$ formation in porcine serum was also tested by the following experiment: Purified human C3 (0.1 g/liter) and zymosan ( $10 \mathrm{~g} /$ liter) were mixed with NPS or MPGN-serum. Aliquots of MPGN-serum were in addition, mixed with $0.1 \mathrm{~g} /$ liter of purified $\mathrm{HFH}$ or purified $\mathrm{PFH}$. The mixtures were incubated for $24 \mathrm{~h}$ at $37^{\circ} \mathrm{C}$. Conversion of human $\mathrm{C} 3$ to $\mathrm{C} 3 \mathrm{c}$ was evaluated by Western blotting using an antiserum against human $\mathrm{C} 3$ which showed insignificant cross-reactivity against porcine C3 by this method.

Double immunodiffusion, agarose gel electrophoresis, and crossed immunoelectrophoresis. Ouchterlony double diffusion and agarose gel electrophoresis were performed with conventional techniques. Crossed immunoelectrophoresis was performed using antisera against human or porcine $\mathrm{FH}$ in the top gel.

$\mathrm{NH}_{2}$-terminal sequencing. The sequencing was done by Professor K. Sletten at the Biotechnology Center, University of Oslo, Norway. $75 \mu \mathrm{g}$ purified PFH ( 500 pmol) was analyzed by automatic Edman
Table I. Test for Nephritic Factor

\begin{tabular}{lrrrr}
\hline & \multicolumn{4}{c}{ Median TCC content (AU/ml) after } \\
\cline { 2 - 5 } \multicolumn{1}{c}{ Sample } & $0 \mathrm{~h}$ & $1 \mathrm{~h}$ & $4 \mathrm{~h}$ & $24 \mathrm{~h}$ \\
\hline NPS + MPGN & 5.9 & 8.8 & 12.9 & 18.5 \\
NPS + healthy & 2.8 & 7.6 & 11.7 & 21.6 \\
NPS + PBS & 2.0 & 6.2 & 9.3 & 26.2 \\
NPS + zymosan & & 183.1 & 197.3 & 171.4 \\
& & & & \\
\hline
\end{tabular}

4 vol NPS were mixed with 1 vol serum from individual MPGN piglets $(n=7)$ or from healthy littermates $(n=7)$ and incubated for $0,1,4$, or $24 \mathrm{~h}$ at $37^{\circ} \mathrm{C}$. The resulting $\mathrm{C}$ activation was evaluated by measuring the TCC concentration of the mixtures. As negative and positive controls, NPS was mixed with PBS $(n=1)$, or zymosan ( $50 \mathrm{~g} /$ liter in PBS, $n=1)$, respectively.

degradation on a 477A Protein Sequencer (Applied Biosystems, Foster City, CA) with an on-line 120A phenylthiohydantoin amino acid derivatives analyzer.

Enzyme immmunoassay for PFH. Microtiterplates (Maxisorp; Nunc, Roskilde, Denmark) were coated with rabbit anti-PFH overnight at $4^{\circ} \mathrm{C}$ (IgG fraction, $2 \mathrm{mg} /$ liter in PBS). Normal porcine plasma was used as standard (twofold dilution 1/500-1/16,000). Plasma samples were assayed diluted $1 / 2,000$ or less. The detection antibodies were mAb 7C3 (2 mg/liter), and peroxidase-linked anti-mouse Ig (diluted 1/ 2,000). The plates were developed using 2,2'-azino-di-[3-ethylbenzthiazolinesulphonate (6)] (Boehringer Mannheim GmbH, Mannheim, Germany) and $\mathrm{H}_{2} \mathrm{O}_{2}$. The standard and samples were diluted in PBS containing $10 \mathrm{mM} \mathrm{Na}_{2}$ EDTA and $0.2 \%$ Tween 20 . Triplicate determinations were done. The antibodies were diluted in PBS containing $0.2 \%$ Tween 20. Incubations were done for $45 \mathrm{~min}$ at $37^{\circ} \mathrm{C}$. Purified $\mathrm{PFH}$ was used for calibration of the assay. This PFH was purified with conventional technique as described followed by affinity purification on the 7C3 immunosorbent and was $100 \%$ pure evaluated from SDS-PAGE. The intraassay and interassay coefficients of variation, $\mathrm{CV}(\mathrm{x})$, were estimated from 12 or 44 measurements, respectively, using the formula $\mathrm{CV}(\mathrm{x})=\mathrm{SD} / \overline{\mathrm{x}}$, where SD is the standard deviation and $\overline{\mathrm{x}}$ is the mean value of the measurements.

\section{Results}

Nephritic factor test. No C-activating factor was detected in the sera from MPGN-affected piglets (Table I). The difference in TCC content at $0 \mathrm{~h}$ was due to the increased amount of preformed TCC in MPGN-sera (Fig. 1).

Transfusion of plasma or erythrocytes. Transfusion of citrated plasma $(30 \mathrm{ml} / \mathrm{kg})$ resulted in a clear decline of circulating TCC (Fig. 1). There was an initial decline during the transfusion which corresponded well to the hemodilution (the TCC concentration of transfused plasma was $\sim 1 \mathrm{AU} / \mathrm{ml}$ ). An additional decline of TCC was observed during the first $8 \mathrm{~h}$ after the transfusion was finished (median decline $56 \%$, range $30-$ $76 \%$ in 11 experiments). $24 \mathrm{~h}$ after the transfusion, the TCC level had started to incline again and reached the pretransfusional level after $3 \mathrm{~d}$.

The $\mathrm{C} 3$ level increased during transfusion since the $\mathrm{C} 3$ concentration of transfused plasma was $\sim 85 \%$. No significant further increase of $\mathrm{C} 3$ was observed after the transfusion was finished. Instead the $\mathrm{C} 3$ level gradually declined, but after $3 \mathrm{~d}$ it still had not reached down to the pretransfusional level.

In young piglets transfusions were typically finished in 10- 


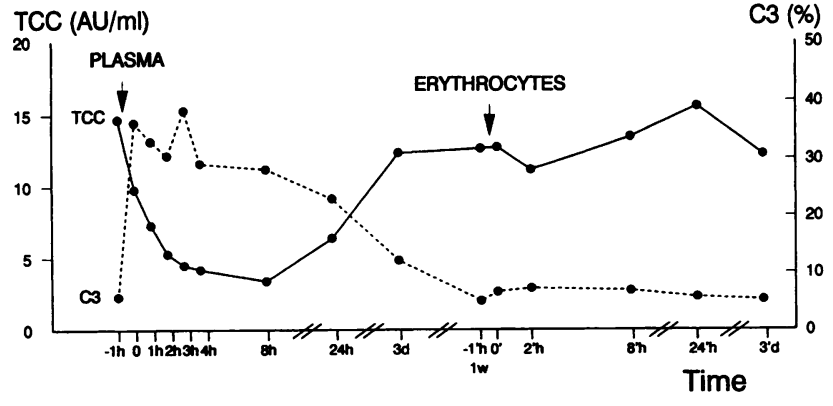

Figure 1. Test for $\mathrm{C}$ inhibitory effect of plasma and erythrocytes in vivo. Citrated plasma (30 ml $/ \mathrm{kg}$ ) was administered intravenously to a MPGN-piglet (wt, $10 \mathrm{~kg}$ ). Samples of EDTA-plasma were obtained before the transfusion $(-1 h)$, immediately after $(0)$, and at several time points after the transfusion. After 1 wk $(1 w k=-1$ ' $h)$ the piglet received a transfusion with washed erythrocytes $(30 \mathrm{ml} / \mathrm{kg}$, hematocrit 0.88 ), which was finished at time $0^{\prime}$. The effect was evaluated by assay of $\mathrm{C} 3$ (broken line, in percentage of normal) and TCC (solid line, in $A U / \mathrm{ml}$ ). Similar profiles were observed after plasma transfusion in all 13 MPGN-piglets, also when repeated. One more piglet received erythrocyte transfusion, with a similar result.

$20 \mathrm{~min}$. Because of poorer tolerance, transfusions were performed slower in older pigs (30-60 $\mathrm{min}$ ). These conditions given, most pigs tolerated weekly plasma transfusions well. However, individual differences were seen. Some piglets showed repeated adverse reactions, which always were dose dependent and usually abated when the speed of transfusion was reduced. Generally, close to one transfusion was given per week until the piglets died.

After transfusion of packed erythrocytes $(30 \mathrm{ml} / \mathrm{kg})$ no significant changes of $\mathrm{C} 3$ and TCC were seen (Fig. 1).

Survival. In the 13 transfused MPGN piglets, median and maximal survival was 82 and $375 \mathrm{~d}$, respectively (Fig. 2). This was significantly longer than previously observed in nontransfused MPGN-affected piglets also surviving the first week ( $n$ $=24$ ), having median and maximal survival of 37 and $72 \mathrm{~d}$,

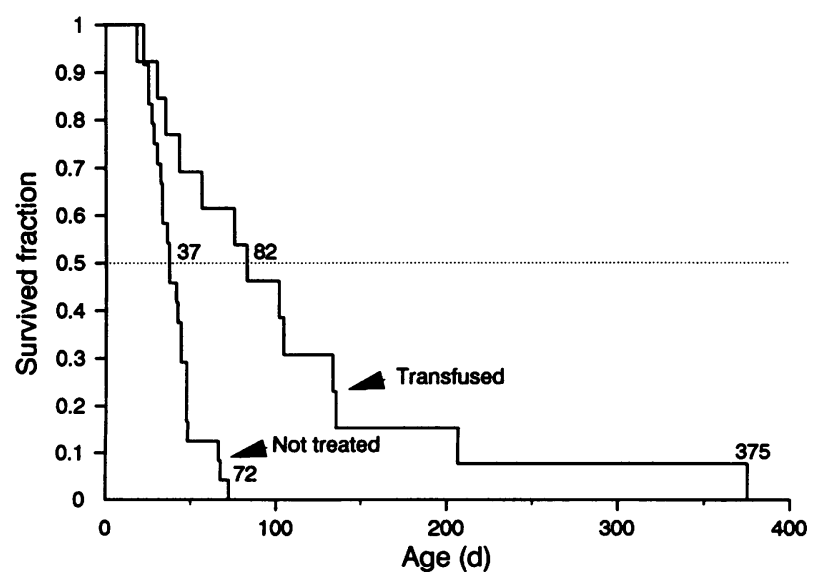

Figure 2. Survival of MPGN-piglets. Kaplan-Meyer plot showing the survival of 24 MPGN-piglets that did not receive any treatment (Not treated) as described previously (16), and of the 13 MPGN-piglets that were treated with plasma transfusions (Transfused). Transfusions were started at $\sim 2$ wk old and generally continued once every week until the piglets died.

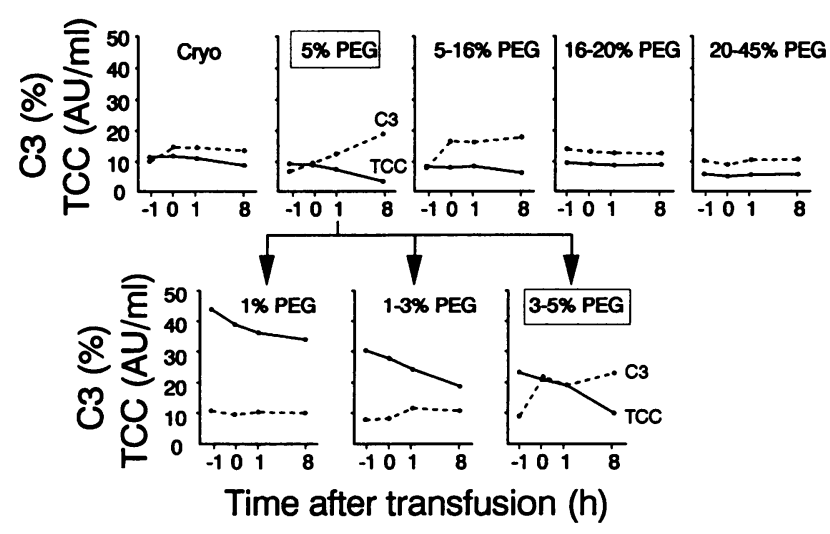

Figure 3. The ability of plasma fractions (precipitates) to inhibit in vivo $\mathrm{C}$ activation in MPGN-piglets. Different plasma fractions (dissolved cryoprecipitate or PEG precipitates) were administered intravenously to MPGN-piglets (weight 3-18 kg). Plasma samples were drawn before the infusion $(-1)$, immediately after the infusion $(0)$, after $1 \mathrm{~h}(1)$, and after $8 \mathrm{~h}(8)$. The effect was evaluated by assay of $\mathrm{C} 3$ (broken line, in percentage of normal) and TCC (solid line, in AU/ml) in these samples. From the first fractionation experiment (top), five fractions were tested. Since the 5\% PEG precipitate showed a superior effect, a narrower precipitation in this range was performed in the second fractionation experiment (bottom).

respectively, (16) $(P=0.005$, Mann-Whitney two sample test). All the nontransfused piglets had died of renal failure. In contrast, only five ( $38 \%$ ) of the transfused piglets died of renal failure. The remaining eight pigs did not have renal failure and died of miscellaneous causes such as hypocalcemia $(n=3)$, complication to blood sampling $(n=1)$, surgical complications $(n=3)$, or unknown $(n=1)$. Postmortem examination of the kidneys from all transfused animals fulfilled the criteria for MPGN type II, but the picture was less proliferative compared to untreated MPGN animals.

Purification of PFH. EDTA plasma was initially fractionated by cryoprecipitation and by sequential PEG precipitation. The $\mathrm{C}$ inhibitory effect of the dissolved precipitates was tested in vivo after intravenous administration to MPGN piglets (Fig. 3 ). The dissolved 3-5\% PEG precipitate showed strongest $C$ inhibitory effect and was regarded to contain the bulk of active protein. This precipitate was therefore further fractionated by ion-exchange chromatography on $\mathrm{Q}$ Sepharose, from which the pooled fractions $48-51$ showed the strongest $C$ inhibitory activity (Fig. 4). A considerable activity was also found in the effluent, probably due to overloading of the column or to the relatively high salt concentration of the sample buffer which probably impaired binding $(100 \mathrm{mM} \mathrm{NaCl})$. The remaining protein of the pooled fractions 48-51 were further fractionated by gel filtration using Sepharose CL-6B (Fig. 4). The pooled gel filtration fractions $68-75$ showed strongest activity and were therefore further fractionated using Resource $Q$, an anion exchange HPLC column. From Resource $Q$, only fraction 9 showed significant activity (Fig. 4). The activity of this fraction was very high, since transfusion of $5 \mathrm{mg} / \mathrm{kg}$ showed an effect comparable to the transfusion of $30 \mathrm{ml} / \mathrm{kg}$ citrated plasma, a calculated concentration effect of $370: 1$ per mg protein. SDSPAGE of this fraction showed a single band at $\sim 150 \mathrm{kD}$ under nonreducing conditions. Under reducing conditions, two additional weaker bands of 50 and $25 \mathrm{kD}$ appeared, indicating contamination of IgG. The fraction was therefore adsorbed on Pro- 

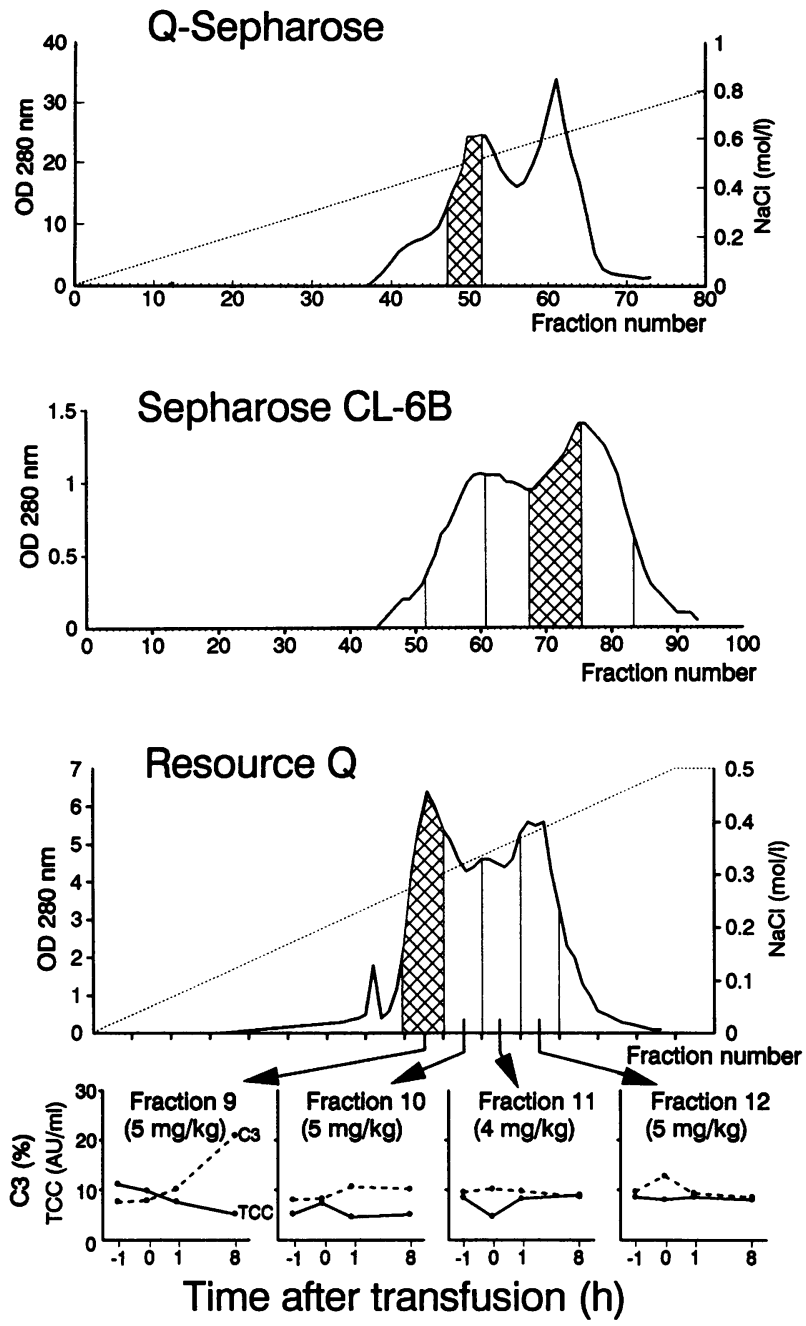

Figure 4. Chromatographic fractionation of plasma. The 3-5\% PEG precipitate (see Fig. 3) was fractionated successively in three chromatographic steps using Q-Sepharose (ion-exchange), Sepharose CL-6B (gel filtration), and Resource Q (HPLC ion-exchange). The ability of each fraction to inhibit in vivo $\mathrm{C}$ activation in MPGN-piglets was tested as described in the legend to Fig. 3. The pool of active fractions from QSepharose was fractionated on Sepharose CL-6B, and the pool of active fractions from Sepharose CL-6B was finally fractionated on Resource $\mathrm{Q}$. The active fractions are cross-hatched, and the results from in vivo activity testing of Resource $Q$ fractions are shown in the lower part of the figure.

tein G Sepharose and after another run on Resource Q, it eluted as a single peak. Evaluated by SDS-PAGE the peak contained a pure single chain $150-\mathrm{kD}$ protein (reducing conditions), indistinguishable from HFH (Fig. 5). From these observations, and from the results following, we conclude that the protein isolated was PFH.

Western blotting. An antiserum against PFH was made by immunizing rabbits. The antiserum reacted strongly with NPS and purified PFH under nonreducing conditions (Fig. 5). The 150-kD PFH was detected as a faint band in sera from all MPGN piglets. The staining of $0.1 \mu \mathrm{l}$ MPGN-serum and 0.1 ng purified PFH was similar, corresponding to an FH content in MPGN-serum of $\sim 1 \mathrm{mg} /$ liter, whereas NPS contained at least 100 times more. In addition to the $150-\mathrm{kD}$ band, the antise- rum also stained a $31-\mathrm{kD}$ band quite strongly, in addition to three barely visible bands of 46,52 , and $74 \mathrm{kD}$. All these light bands were equally strong in MPGN-sera and in normal sera. The 31-kD band was definitely not present in the purified PFH (which was the immunisate), but bands similar to the faint ones were seen (Fig. 5). Under reducing conditions only a faint 150$\mathrm{kD}$ band was seen (not shown). The antiserum did not stain 1 $\mu \mathrm{g}$ porcine IgG, purified by protein A chromatography, which probably corresponded to more IgG than was the content of the serum samples.

The anti-PFH showed some reaction against normal human serum (NHS) and purified HFH (Fig. 5). Similarly, the antiserum agaist HFH showed reaction against both NPS and purified $\mathrm{PFH}$, revealed as $150-\mathrm{kD}$ bands. Anti-HFH also detected three weak bands of 37,40 , and $43 \mathrm{kD}$ in NHS, probably corresponding to the gene products of an FH-related gene $(23,24)$.

The mAb 7C3 against PFH was isotyped to be IgG1-kappa. Its specificity was tested in Western blotting against NPS; it only reacted against the $150-\mathrm{kD}$ protein (not shown).

C3c formation in vivo and in vitro. Low amounts of $\mathrm{C} 3$ were detected in MPGN plasma by Western blotting. C3c was clearly present both in healthy and MPGN plasma, indicating in vivo $\mathrm{C} 3 \mathrm{c}$ formation, excluding a primary factor I deficiency in the MPGN piglets (not shown). In vitro $\mathrm{C} 3 \mathrm{c}$ formation was evaluated by incubating NPS and MPGN serum with zymosan $(10 \mathrm{mg} / \mathrm{ml})$ at $37^{\circ} \mathrm{C}$ for $24 \mathrm{~h}$. In NPS large amounts of $\mathrm{C} 3 \mathrm{c}$ appeared by this treatment, but since MPGN serum contained only small amounts of $\mathrm{C} 3$, the degree of $\mathrm{C} 3 \mathrm{c}$ formation induced by zymosan activation was difficult to evaluate by this method (not shown). This problem was evaded by mixing the sera with purified human $\mathrm{C} 3$ before zymosan activation, using an antiserum specific for human C3 in the detection system. NPS converted almost all human $\mathrm{C} 3$ to $\mathrm{C} 3 \mathrm{c}$ during zymosan activation, in contrast to the MPGN-serum where C3c formation was hardly detectable (Fig. 6). However, when MPGN-serum was reconstituted with purified HFH or purified PFH before zymosan activation, large amounts of C3c were formed (Fig. 6).

Double immunodiffusion, agarose gel electrophoresis, and crossed immunoelectrophoresis. In Ouchterlony double diffusion goat antiserum to HFH gave a faint precipitate with a reaction of identity between NPS and purified PFH. The rabbit antiserum to $\mathrm{PFH}$ showed a strong reaction of identity with NPS and purified PFH, but no precipitate line was observed against MPGN-serum, NHS, or purified HFH. In agarose gel electrophoresis, purified PFH migrated corresponding to the $\beta 2$ region showing lower electrophoretic mobility than purified HFH that migrated corresponding to the $\beta 1$-region. To rule out a change in mobility of PFH or HFH due to the purification procedures, crossed immunoelectrophoresis was performed, using NPS or NHS as sample and anti-PFH or anti-HFH in the top gel. This experiment confirmed the lower electrophoretic mobility of the porcine protein.

$\mathrm{NH}_{2}$-terminal sequence. The specific signal was weak and the background level comparatively high in the first batch of purified PFH tested. This problem might be caused by contaminants, extensive protein polymorphism, or degradation. We therefore also purified PFH basically as described, but included affinity chromatography on the 7C3-immunosorbent as a final step. We also purified PFH rapidly from one pig using the 7C3immunosorbent to avoid protein polymorphism and degradation. No contaminants of these new PFH batches could be detected in SDS-PAGE, but the modifications did not solve the 


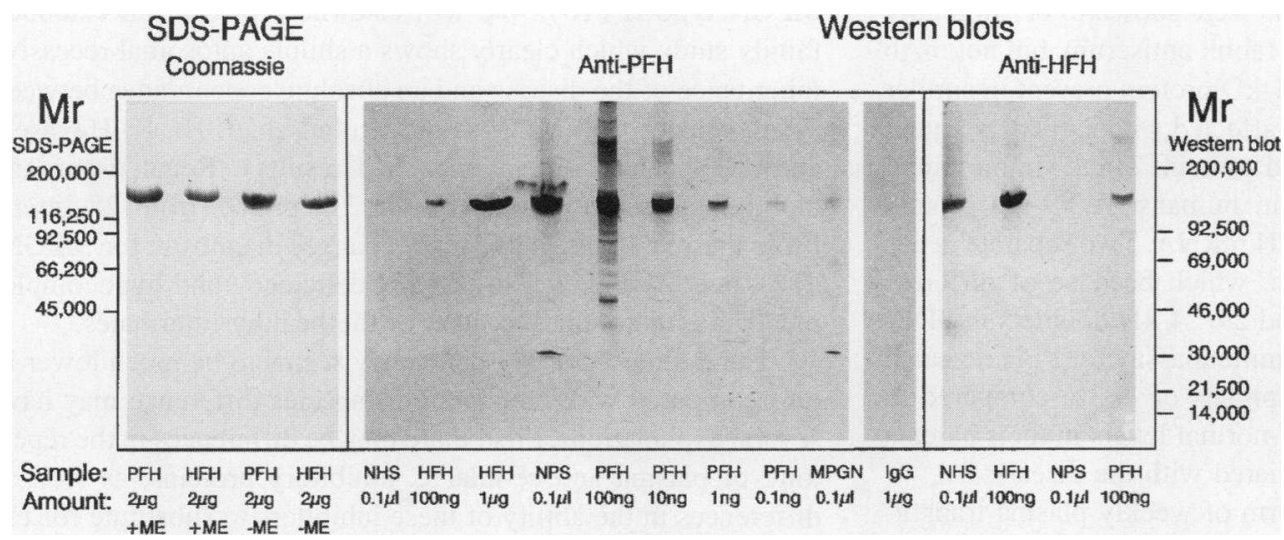

Figure 5. SDS-PAGE and western blots of PFH and HFH. In SDSPAGE (first four lanes), $2 \mu \mathrm{g}$ of purified protein was run per lane and subsequently stained with Coomassie brilliant blue $\mathrm{R}$. The proteins were reduced with mecaptoethanol $(+M E)$, or not reduced $(-M E)$. All remaining samples ( sera or purified proteins) were run under nonreducing conditions, blotted onto nitrocellulose, and stained either with rabbit anti-PFH or goat anti-HFH. MPGN, serum from MPGN piglet; IgG, porcine IgG. problems. However, in the initial 17 steps, the residue was determined with certainty in nine positions. Three positions were uncertain and five residues could not be determined, including the initial four positions. The $\mathrm{NH}_{2}$-terminal sequence determined was compared with the sequences for human and murine $\mathrm{FH}$ as determined by cDNA cloning $(25,26)$, and the sequence of rabbit $\mathrm{FH}$ as determined by automated Edman degradation (Fig. 7) (27). In the 12 positions determined there was $58 \%$ homology with human, murine, and rabbit FH.

Enzyme immunoassay for PFH. The intraassay and interassay coefficients of variation were 1.7 and $5.2 \%$, respectively. Normal porcine plasma was determined to contain 215 $\mathrm{mg} /$ liter FH. In adult Landrace pigs $(n=20)$, which were not associated with hereditary MPGN type II, median FH concentration was $227 \mathrm{mg} /$ liter (range 200-255 mg/liter). The parents of the FH-deficient piglets $(n=8)$ had a median FH concentration of $98 \mathrm{mg} /$ liter (range $64-135 \mathrm{mg} /$ liter). Plasma samples of 4-10-d-old piglets were analyzed. The deficient piglets ( $n$

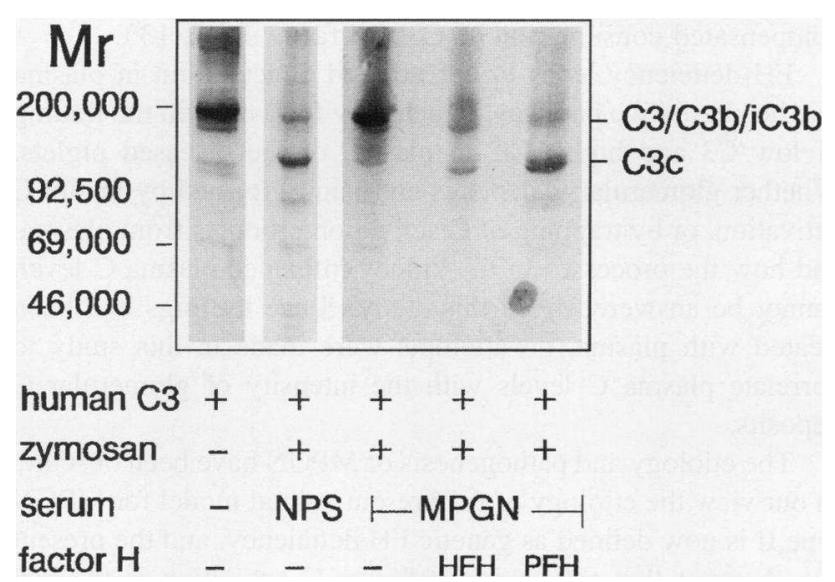

Figure 6. Factor I cofactor activity in porcine serum. NPS or MPGNserum $(M P G N)$ was mixed with purified human C3 $(0.1 \mathrm{~g} /$ liter $)$ and zymosan $(10 \mathrm{~g} /$ liter $)$, with or without the addition of purified HFH or PFH $(0.1 \mathrm{~g} /$ liter). The mixtures (not C3 only) were incubated for 24 $\mathrm{h}$ at $37^{\circ} \mathrm{C}$ before SDS-PAGE was performed under nonreducing conditions using $0.1 \mu \mathrm{l}$ sample per lane. The gel was blotted onto nitrocellulose and stained with goat anti-human C3 (diluted $10^{-3}$ ) and horseradish peroxidase-linked mouse anti-goat $\operatorname{Ig}\left(\right.$ diluted $10^{-3}$ ). The antiserum against human $\mathrm{C} 3$ showed insignificant cross-reactivity against porcine C3 in Western blotting.
= 13) had a median FH concentration of $1.6 \mathrm{mg} /$ liter (range 1.1-2.3 mg/liter), compared to $51 \mathrm{mg} /$ liter in their healthy littermates ( $n=52$, range $26-98 \mathrm{mg} /$ liter).

\section{Discussion}

We have previously suggested that hereditary porcine MPGN type II may be caused by deficiency of a $\mathrm{C}$ regulatory protein (17). $\mathrm{C}$ regulatory proteins may be divided into those present in plasma and those attached to cellular membranes, and several such regulators are known in humans. Plasma regulators are $\mathrm{Cl}$ inhibitor, C4b binding protein, factor $\mathrm{D}, \mathrm{FH}$, factor $\mathrm{I}$, factor $\mathrm{J}$, properdin, vitronectin, and clusterin. Membrane-bound regulators are decay-accelerating factor, membrane cofactor protein, complement receptor type 1 , homologous restriction factor, glycophorin A and CD59. The density of membrane bound regulators varies considerably between different types of cells, but all cells probably express at least some of them.

Initial transfusion experiments clearly demonstrated that the deficient regulatory protein of MPGN piglets was present in plasma from normal pigs and not on erythrocytes. By fractionating normal porcine plasma and monitoring the $\mathrm{C}$ inhibitory activity of the fractions in vivo, we finally found that the activity was confined to one single protein. Intravenous administration of $5 \mathrm{mg} / \mathrm{kg}$ of this protein showed a similar C inhibitory effect as the transfusion of $30 \mathrm{ml} / \mathrm{kg}$ of citrated plasma, indicating a normal plasma concentration of the protein of $\sim 200 \mathrm{mg} / \mathrm{liter}$. The single chain protein had a mol wt of $150 \mathrm{kD}$, showed factor I cofactor activity in vitro, showed immunologic cross-reactivity with $\mathrm{HFH}$, and the $\mathrm{NH}_{2}$-terminal amino acid sequence was homologous with human, murine, and rabbit FH. Taken together these data strongly indicate that the purified protein was PFH.

Specific antibodies against PFH were produced. In Western

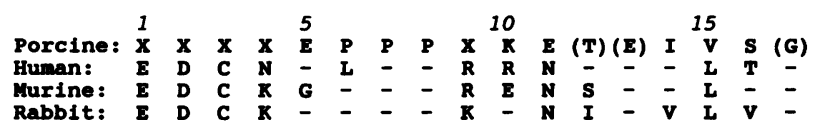

Figure 7. $\mathrm{NH}_{2}$-terminal sequences (from the left) of porcine, human, murine, and rabbit FH. The sequences for porcine and rabbit proteins have been determined by automated Edman degradation, whereas the sequences of the human and murine proteins have been deduced from cDNA clones (25-27). X, residue which we could not determine; ( ), uncertain residue; - , residue identical to the porcine residue. 
blotting all MPGN-affected piglets were shown to be subtotally deficient in the $150-\mathrm{kD}$ PFH. The rabbit antiserum, but not $\mathrm{mAb}$ $7 \mathrm{C} 3$, in addition reacted with a $31-\mathrm{kD}$ protein present in similar amounts in healthy and MPGN-affected piglets. This protein probably represents an FH related protein. Three similar small FH-related proteins are known in humans. A 49-kD protein occurs by alternative splicing of FH mRNA. Two separate genes encode for one polypeptide each, which because of different glycosylation, occur as 42/37- and 29/24-kD doublets in SDSPAGE $(23,28,29)$. An enzyme immunoassay for $\mathrm{PFH}$ revealed levels of FH in MPGN-affected piglets of $\sim 3 \%$ compared to their healthy littermates, and half-normal levels in their parents compared to adult pigs not associated with the disease.

Substitution therapy in the form of weekly plasma transfusions significantly improved survival of the MPGN-affected piglets. The used dose (mainly $30 \mathrm{ml} / \mathrm{kg}$ ) was, however, insufficient to normalize the level of $\mathrm{C}$ activation, revealed as persistent supranormal TCC (Fig. 1). Furthermore, hardly any remaining $\mathrm{C}$ inhibitory effect was seen $3 \mathrm{~d}$ after a transfusion. This shows that relatively modest amounts of $\mathrm{FH}$ was needed to convert the MPGN into a nonlethal course.

Hereditary FH deficiency has been reported in 12 human beings. Two of these had clearly defined MPGN type II, five presented other types or undefined MPGN. Levy et al. (7) described two brothers presenting with hematuria at 14 and 4 mo old, respectively. Electron microscopic evaluation of renal biopsies revealed MPGN type II in both. Their FH levels were $\sim 10 \%$ of normal. Thompson and Winterborn described an 8 mo-old boy who presented hemolytic uremic syndrome and his 3-yr-old healthy brother (13). Both had low amounts of FH in serum, 6 and $7 \%$ of normal value, respectively. Electron microscopic evaluation of a renal biopsy from the proband revealed capillary wall thickening due to subendothelial deposits, agreeing with MPGN type I. Lopez-Larrea et al. described three siblings with undetectable $\mathrm{FH}(<5 \%)$ who all presented MPGN, not further specified (14). Brai et al. described three siblings with undetectable FH $(<1 \%)$. One of these also had a partial C2 deficiency and presented SLE with nephritis (15). Nielsen et al. described a 15-yr-old girl with no detectable FH in plasma $(<1 \%)$. She presented two episodes of meningococcal disease, but was otherwise completely healthy (11). Fijen et al. described an FH-deficient SLE patient who presented with meningococcal disease (30). A functional FH deficiency associated with MPGN type II (atypical) was described by Meri et al. (31). This patient had a monoclonal $\lambda$ light chain that bound $\mathrm{FH}$ and interferred with its $\mathrm{C}$ inhibitory function.

MPGN type II is a rare condition, and FH deficiency is extremely rare in humans. The association of the two conditions as observed in a few individuals may suggest a causal relationship. This is supported by the observation that plasma factors which block FH function, either by binding to the alternative C3 convertase, or by binding to $\mathrm{FH}$ itself, also are associated with MPGN type II $(5,31)$. It is notable, however, that human beings with complete $\mathrm{FH}$ deficiency have a good chance to be spared from kidney disease. Furthermore, many patients with C3 nephritic factor present with other types of glomerulonephritis than MPGN type II (1), and some of them have no signs of glomerulonephritis at all (32).

In the described FH deficiency in pigs, all affected animals (homozygous deficient) developed renal failure within a few weeks of birth. The disease invariably followed a lethal course, and the renal morphology was consistently compatible with
MPGN type II (16). We will elsewhere present an extended family study which clearly shows a simple autosomal recessive inheritance of the disease and an absolute concordance between FH deficiency and MPGN type II (Jansen, J. H., K. Høgåsen, and A. M. Grøndahl, unpublished results). Renal tissue and blood samples were available in 239 piglets from 28 litters. From these, 64 piglets had renal changes diagnostic for MPGN. The same 64 piglets also had FH deficiency and hypocomplementemia, in contrast to none of the healthy littermates.

The tolerance for FH deficiency seems to be much lower in pigs compared with humans. This species difference may have several explanations. First, there may be differences in the répertoire of plasma and cellular $\mathrm{C}$ inhibitory proteins, as well as differences in the ability of these inhibitors to substitute for $\mathrm{FH}$ deficiency. Second, there may be differences in the amount of $\mathrm{C}$ components and their tendency for spontaneous activation. Third, there may be differences in the degree of $\mathrm{C}$ compatibility of host surfaces; to what degree host surfaces fail to amplify alternative pathway $\mathrm{C}$ activation. Fourth, the MPGN-affected piglets might have a nephritogenic genetic deficiency in addition to the FH deficiency. The last explanation is improbable, since our extensive family study showed no examples of discrepancy between FH deficiency and MPGN.

Our data provide some information about the kinetics of $\mathrm{C}$ activation products. They confirm that TCC has a short $t_{1 / 2}$ in vivo. This $t_{1 / 2}$ has been estimated to $30-50 \mathrm{~min}$ in rabbits (33) and $50 \mathrm{~min}$ in humans (34). A relatively high concentration of FH was necessary to suppress $\mathrm{C}$ activation in vivo since $30 \mathrm{ml} /$ $\mathrm{kg}$ corresponds to about half the normal plasma volume in piglets. Even this amount of plasma was insufficient to normalize TCC, and the effect lasted $<3 \mathrm{~d}$, indicating that most of the infused $\mathrm{FH}$ was consumed during this period. Since the $t_{1 / 2}$ of $\mathrm{FH}$ in man is $\sim 76 \mathrm{~h}(35)$, our data may indicate either shorter $t_{1 / 2}$ of FH in piglets, or alternatively, an increased metabolism of FH in MPGN-affected piglets. However, our data agree with the finding that FH levels $\sim 10 \%$ are associated with considerably increased activity in the alternative pathway with uncompensated consumption of $\mathrm{C} 3$ and factor $\mathrm{B}(7,13)$.

FH deficiency leads to unrestricted $\mathrm{C}$ activation in plasma via the alternative pathway, which may fully explain the finding of low C3 and high TCC in plasma of the diseased piglets. Whether glomerular $\mathrm{C}$ deposits are mainly formed by in situ $\mathrm{C}$ activation, or by trapping of $\mathrm{C}$ activation products from plasma, and how the processes in the kidney influence plasma $\mathrm{C}$ level, cannot be answered from this study. Since the pigs had been treated with plasma, no attempts were made in this study to correlate plasma $\mathrm{C}$ levels with the intensity of glomerular $\mathrm{C}$ deposits.

The etiology and pathogenesis of MPGN have been obscure. In our view the etiology of the present animal model for MPGN type II is now defined as genetic FH deficiency, and the present data suggest that alternative pathway $\mathrm{C}$ activation is the key event in the pathogenesis of MPGN type II.

\section{Acknowledgments}

Excellent technical assistance was provided by Bente Falang Hoaas, Merethe Sanna, and Iren Anette Hatlehol. The staff at Gilde Fellesslakteriet, Oslo, kindly provided us with porcine blood.

This work was supported by Medinnova, Oslo. 


\section{References}

1. Holley, K. E., and J. V. Donadio, Jr. 1994. Membranoproliferative glomerulonephritis. In Renal Pathology. C. C. Tisher and B. M. Brenner, editors. J. B. Lippincott Co., Philadelphia. 294-329.

2. Habib, R., C. Kleinknecht, M. C. Gubler, and M. Levy. 1973. Idiopathic membranoproliferative glomerulonephritis in children. Report of 105 cases. Clin. Nephrol. 1:194-214.

3. Strife, C. F., P. T. McEnery, A. J. McAdams, and C. D. West. 1977. Membranoproliferative glomerulonephritis with disruption of the glomerular basement membrane. Clin. Nephrol. 7:65-72.

4. Jackson, E. C., A. J. McAdams, C. F. Strife, J. Forristal, T. R. Welch, and C. D. West. 1987. Differences between membranoproliferative glomerulonephritis type I and III in clinical presentation, glomerular morphology, and complement perturbation. Am. J. Kidney Dis. 9:115-120.

5. Daha, M. R., D. T. Fearon, and K. F. Austen. 1976. C3 nephritic factor (C3NeF): stabilization of fluid phase and cell-bound alternative pathway convertase. J. Immunol. 116:1-7.

6. Mollnes, T. E., Y. C. Ng, D. K. Peters, T. Lea, J. Tschopp, and M. Harboe. 1986. Effect of nephritic factor on $\mathrm{C} 3$ and on the terminal pathway of complement in vivo and in vitro. Clin. Exp. Immunol. 65:73-79.

7. Levy, M., L. Halbwachs-Mecarelli, M. C. Gubler, G. Kohout, A. Bensenouci, P. Niaudet, G. Hauptmann, and P. Lesavre. 1986. H deficiency in two brothers with atypical dense intramembranous deposit disease. Kidney Int. 30:949-956.

8. Weiler, J. M., M. R. Daha, K. F. Austen, and D. T. Fearon. 1976. Control of the amplification convertase of complement by the plasma protein $\beta 1 \mathrm{H}$. Proc. Natl. Acad. Sci. USA. 73:3268-3272.

9. Whaley, K., and S. Ruddy. 1976. Modulation of C3b hemolytic activity by a plasma protein distinct from C3b inactivator. Science (Wash. DC). 193:10111013.

10. Whaley, K., and S. Ruddy. 1976. Modulation of the alternative complement pathway by $\beta 1 \mathrm{H}$ globulin. J. Exp. Med. 144:1147-1163.

11. Nielsen, H. E., K. C. Christensen, C. Koch, B. S. Thomsen, N. H. H. Heegaard, and J. Tranum-Jensen. 1989. Hereditary, complete deficiency of complement factor $\mathrm{H}$ associated with recurrent meningococcal disease. Scand. $J$. Immunol. 30:711-718.

12. Ross, G. D., J. D. Lambris, J. A. Cain, and S. L. Newman. 1982. Generation of three different fragments of bound $\mathrm{C} 3$ with purified factor I or serum. I. Requirements for factor H vs CR1 cofactor activity. J. Immunol. 129:2051-2060.

13. Thompson, R. A., and M. H. Winterborn. 1981. Hypocomplementaemia due to a genetic deficiency of beta 1H globulin. Clin. Exp. Immunol. 46:110119.

14. Lopez-Larrea, C., M. A. Dieguez, A. Enguix, O. Dominguez, B. Marin, and E. Gomez. 1987. A familial deficiency of complement factor H. Biochem. Soc. Trans. 15:648-649.

15. Brai, M., G. Misiano, S. Maringhini, I. Cutaja, and G. Hauptmann. 1988. Combined homozygous factor $\mathrm{H}$ and heterozygous $\mathrm{C} 2$ deficiency in an Italian family. J. Clin. Immunol. 8:50-56.

16. Jansen, J. H. 1993. Porcine membranoproliferative glomerulonephritis with intramembranous dense deposits (porcine dense deposit disease). APMIS. 101:281-289.

17. Jansen, J. H., K. Høgåsen, and T. E. Mollnes. 1993. Extensive complement activation in hereditary porcine membranoproliferative glomerulonephritis typeII (porcine dense deposit disease). Am. J. Pathol. 143:1356-1365.

18. Jansen, J. H., and K. Nordstoga. 1992. Renal lesions in Norwegian slaughter pigs. Macroscopic and light microscopic studies. J. Vet. Med. 39:582-592.

19. Mollnes, T. E., T. Lea, M. Harboe, and J. Tschopp. 1985. Monoclonal antibodies recognizing a neoantigen of poly (C9) detect the human terminal complement complex in tissue and plasma. Scand. J. Immunol. 22:183-195.

20. Hammer, C. H., G. H. Wirtz, L. Renfer, H. D. Gresham, and B. F. Tack. 1981. Large scale isolation of functionally active components of the human complement system. J. Biol. Chem. 256:3995-4006.

21. Sim, R. B., and R. G. DiScipio. 1982. Purification and structural studies on the complement-system control protein $\beta 1 \mathrm{H}$ (Factor H). Biochem. J. 205:285293.

22. Galfre, G., and C. Milstein. 1981. Preparation of monoclonal antibodies; strategies and procedures. In Methods in Enzymology. Vol. 73. J. J. Langone and H. Van Vunatis, editors. Academic Press, New York. 3-46.

23. Estaller, C., V. Koistinen, W. Schwaeble, M. P. Dierich, and E. H. Weiss. 1991. Cloning of the 1.4-kb mRNA species of human complement factor $\mathrm{H}$ reveals a novel member of the short consensus repeat family related to the carboxy terminal of the classical 150-kDa molecule. J. Immunol. 146:3190-3196.

24. Zipfel, P. F., and C. Skerka. 1994. Complement factor $\mathrm{H}$ and related proteins: an expanding family of complement-regulatory proteins? Immunol. Today. 15:121-126.

25. Kristensen, T., and B. F. Tack. 1986. Murine protein $H$ is comprised of 20 repeating units, 61 amino acids in length. Proc. Natl. Acad. Sci. USA. 83:39633967.

26. Ripoche, J., A. J. Day, T. J. Harris, and R. B. Sim. 1988. The complete amino acid sequence of human complement factor H. Biochem. J. 249:593-602.

27. Choi, N. H., and $M$. Tomita. 1988. Amino acid sequence of rabbit factor $H$ of complement. Purification of peptides produced by cyanogen bromide cleavage. Chem. \& Pharm. Bull. (Tokyo). 36:3008-3011.

28. Estaller, C., W. Schwaeble, M. Dierich, and E. H. Weiss. 1991. Human complement factor $\mathrm{H}$ : two factor $\mathrm{H}$ proteins are derived from alternatively spliced transcripts. Eur. J. Immunol. 21:799-802.

29. Skerka, C., C. Timmann, R. D. Horstmann, and P. F. Zipfel. 1992. Two additional human serum proteins structurally related to complement factor $\mathrm{H}$ : evidence for a family of factor $\mathrm{H}$-related genes. J. Immunol. 148:3313-3318.

30. Fijen, C. A., E. J. Kuijper, A. J. Hannema, A. G. Sjöholm, and J. P. van Putten. 1989. Complement deficiencies in patients over ten years old with meningococcal disease due to uncommon serogroups. Lancet. ii:585-588.

31. Meri, S., V. Koistinen, A. Miettinen, T. Tornroth, and I. J. T. Seppala. 1992. Activation of the alternative pathway of complement by monoclonal lambda light chains in membranoproliferative glomerulonephritis. J. Exp. Med. 175:939950.

32. Power, D. A., Y. C. Ng, and J. G. Simpson. 1990. Familial incidence of C3 nephritic factor, partial lipodystrophy and membranoproliferative glomerulonephritis. Q. J. Med. 75:387-98.

33. Hugo, F., C. Berstecher, S. Kramer, W. Fassbender, and S. Bhakdi. 1989. In vivo clearance studies of the terminal fluid-phase complement complex in rabbits. Clin. Exp. Immunol. 77:112-116.

34. Mollnes, T. E. 1985. Early- and late-phase activation of complement evaluated by plasma levels of $\mathrm{C} 3 \mathrm{~d}, \mathrm{~g}$ and the terminal complement complex. Complement. 2:156-164.

35. Charlesworth, J. A., D. M. Scott, B. A. Pussell, and D. K. Peters. 1979. Metabolism of human $\beta 1 \mathrm{H}$ : studies in man and experimental animals. Clin. Exp. Immunol. 38:397-404. 